\title{
Systemic Therapy of Dystonia
}

\author{
Stanley Fahn
}

\begin{abstract}
A number of pharmacologic agents have been found to be effective for the dystonias. Anticholinergic drugs have been shown to be the most effective in terms of percentage of subjects who receive moderate to marked benefit. About $50 \%$ of children and $40 \%$ of adults obtain such improvement. Peripheral adverse effects are usually overcome by pyridostigmine. It may be necessary to utilize pilocarpine eyedrops for blurred vision. Central adverse effects, such as forgetfulness, can be reduced only by a reduction in dosage of the anticholinergic. In comparing trihexyphenidyl and ethopropazine, we found that children tend to have better tolerance of the former and adults tend to have better tolerance of the latter. The antidopaminergics are the group of drugs that were found to be the next most effective agents in terms of percentage of patients who respond. However, these drugs, particularly the dopamine receptor blockers, have the capacity to induce tardive dyskinesia and tardive dystonia. Tardive syndromes are difficult to treat and can persist indefinitely. Other agents that have shown usefulness in controlling dystonia are levodopa, baclofen, carbamazepine, and the benzodiazepines, either alone or in combination with each other and with the anticholinergics. Stereotactic thalamotomy is particularly useful in contralateral hemidystonia. The risk of adverse effects is less than with bilateral thalamotomy, which may need to be employed when generalized dystonia is severely disabling and not responsive to pharmacotherapy.
\end{abstract}

RÉSUMÉ: Traitement systémique de la dystonie. Un certain nombre d'agents pharmacologiques se sont avérés efficaces dans le traitement des dystonies. Il a été démontré que les anticholinergiques sont les agents les plus efficaces si l'on considère le pourcentage de sujets qui en tirent un bénéfice de modéré à important. A peu près $50 \%$ des enfants et $40 \%$ des adultes obtiennent une telle amélioration. Les effets secondaires périphériques sont habituellement soulagés par la pyridostigmine. Il est parfois nécessaire d'utiliser la pilocarpine sous forme de collyre si la vision est embrouillée. Les effets secondaires centraux, tels les déficits de la mémoire, peuvent être réduits seulement par une diminution de la dose d'anticholinergique. Si l'on compare le trihexyphenidyl et l'ethopropazine, nous avons constaté que les enfants en général tolèrent mieux le premier alor que les adultes tolèrent mieux le second. Les agents antidopaminergiques sont le groupe de médicaments qui se sont avérés être les agents les plus efficaces après les anticholinergiques en terme de pourcentage de patients qui y répondent. Cependant, ces médicaments, particulièrement les inhibiteurs des récepteurs dopaminergiques, peuvent induire des dyskinésies tardives et de la dystonie tardive. Ces syndromes tardifs sont difficiles à traiter et peuvent persister indéfiniment. Parmi les autres agents qui se sont avérés utiles dans le contrôle de la dystonie, mentionnons la lévodopa, le baclofen, la carbamazépine, et les benzodiazépines, soit seules ou en combinaison les uns avec les autres, et avec les anticholinergiques. La thalamotomie stéréotaxique est particulièrement utile dans l'hémidystonie contralatérale. Les risques d'effets secondaires sont moindres que pour la thalamotomie bilatérale; celle-ci doit parfois être utilisée quand la dystonie généralisée cause un handicap sévère et ne répond pas à la pharmacothérapie.

Can. J. Neurol. Sci. 1987; 14:528-532

Torsion dystonia refers to sustained, usually twisting, movements that are frequently repetitive, and can progress to prolonged abnormal postures or stabilize to less forceful, but continued movements. 'Torsion dystonia can progress to a state of fixed, forceful, sustained postures or can stablize at any point of progression. Although commonly considered to be slow in speed, the velocity of the abnormal movement varies widely from slow (athetotic dystonia) to shock-like (myoclonic dystonia). In general, the movements are continual and often repetitive. When rhythmic, the term myorhythmia has been used to describe them, ${ }^{2}$ but this term can mean different things and is ambiguous.

Etiologically, torsion dystonia is divided into two categories: idiopathic and symptomatic. The latter often begins as fixed postures (tonic form), but idiopathic dystonia usually begins when the affected body part is carrying out a voluntary action (action dystonia) and is not present when that body part is at rest. With progression of the disorder, dystonic movements can appear when other parts of the body are voluntarily moving (overflow), and with further progression, the dystonic movements can be present when the affected body part is "at rest." Idiopathic dystonic movements can eventually end up as a kinetic (clonic) form or as the tonic form.

When a single body part is affected, the condition is referred to as focal dystonia. Involvement of two or more contiguous regions of the body is referred to as segmental dystonia. Generalized dystonia indicates involvement of one or both legs, the trunk, and some other part of the body.' Progression from a 
focal to segmental to generalized dystonia occurs most commonly the younger the age at onset, whereas the older the age at onset, the more likely the disorder will stabilize and not progress.

\section{Pharmacotherapy}

A number of pharmacologic agents have been found to be effective for the dystonias, but benefit is quite variable. ${ }^{3}$ Strategies have been developed for drug treatment of specific focal dystonias (such as blepharospasm, spasmodic torticollis, and writer's cramp), varieties of segmental dystonia, and generalized dystonia. However, at present there is no good evidence that one type of idiopathic dystonia responds differently from another type in terms of pharmacologic effectiveness. Accordingly, this section will describe the pharmacotherapy of all types of dystonia, organized by classes of drugs. Next, I will discuss my approach to drug selection. Tardive dystonia, a type of dystonia due to dopamine receptor blocking drugs, ${ }^{4}$ requires separate commentary. This section will cover aspects of drugs that have been found to be useful in general.

\section{Anticholinergics}

Since their introduction for dystonia, high-dosage anticholinergic drugs have become one of the mainstays of nonspecific therapy in dystonia. Based originally on open-label trials, ${ }^{5.6}$ the efficacy of these drugs given in high dosages has been substantiated by double-blind investigations ${ }^{7}$ and by other openlabel trials on large numbers of patients. ${ }^{8-10}$ In general, all these studies show that approximately $50 \%$ of children and $40 \%$ of adults with idiopathic dystonia obtain moderate to dramatic benefit from this class of drugs.

It is not clear if the various centrally acting anticholinergics differ from each other in their effectiveness. However, it appears that children tolerate trihexyphenidyl (Artane) better than ethopropazine (Parsidol), while the reverse has been observed for adults.".

Dose-limiting problems with anticholinergics are their peripheral and central adverse effects. Peripheral adverse effects such as dry mouth and blurred vision are fairly common, but can often be ameliorated by co-administration of peripherally acting anticholinesterase drugs and eyedrops of pilocarpine, a muscarinic agonist. Central adverse effects such as forgetfulness, confusion, hallucinations, or behavioral changes can be overcome only by reducing the dose, and thus lessening the usefulness of the drug.

In order to minimize adverse effects, I start with a low dose of an anticholinergic agent and increase the dosage gradually. For children I start with trihexyphenidyl, $2.5 \mathrm{mg}$ b.i.d., and increase the daily dosage by $2.5 \mathrm{mg}$ every week. At daily dosages of, for example, $20,30,40$, or $50 \mathrm{mg} /$ day, I hold the dose constant for four weeks before increasing it further, since some patients have a delay before they respond. I maintain the minimum dose that provides adequate benefit. If no benefit is seen, I increase the dose until intolerable adverse effects are encountered. Antidotes for some of the adverse peripheral effects are discussed above. The dosage of ethopropazine is approximately 10 times greater than that of trihexyphenidyl; otherwise the dosing strategy is identical. If anticholinergics provide any benefit, but higher doses cannot be used because of intolerable side effects, then the optimum dose achieved is maintained and a second drug is added.

\section{Dopaminergics}

There have been a number of reports evaluating levodopa and dopamine agonists in generalized and focal idiopathic torsion dystonia. These have been reviewed recently by Lang. ${ }^{12}$ Only a small percentage of patients with dystonia have shown a favorable response to these agents.

However, patients with diurnal fluctuations of dystonia, the so-called Segawa ${ }^{13}$ variant in which patients tend to be normal in the morning and progressively worsen as the day continues, usually obtain a dramatic response to low-dosage levodopa or dopamine agonists. ${ }^{13-15}$ Recently, Nygaard et al ${ }^{16}$ reported that approximately $5 \%$ to $10 \%$ of patients with childhood-onset dystonia beginning in the legs, with or without diurnal fluctuations, can respond dramatically to low-dosage levodopa. It is not clear if patients responding to levodopa would also respond to anticholinergics. However, it does appear that some patients with diurnal fluctuations of dystonia also respond to low-dosage anticholinergics ${ }^{17.18}$ (and personal observations). Because anticholinergics sometimes interfere with memory (see above), levodopa may be the preferred therapy for these patients.

From various reports, it appears that direct-acting dopamine agonists have approximately the same efficacy as levodopa. ${ }^{19-22}$ Although the response rate to these drugs is quite low, there have been no reports comparing the same patients with different dopamine agonists, and also no comparisons with levodopa and anticholinergics. In the study reported by Greene et al," levodopa and dopamine agonists were used predominantly in patients who had failed to obtain adequate response to anticholinergics. These authors reported that $12 \%$ of 41 patients tested with dopamine agonist therapy had a favorable response. These authors also reported that many patients who had failed previous trials of levodopa responded to anticholinergic therapy. It suggests there is a smaller percentage of dystonic patients responding favorably to dopaminergics compared to anticholinergics. Nevertheless, in the small number of patients who respond favorably to low-dosage levodopa or dopamine agonists, the response can be dramatic, and there is less potential for adverse effects. Thus, it is worth trying levodopa for a short period in all patients with childhood-onset dystonia before proceeding to anticholinergic therapy (discussed further below).

\section{Antidopaminergics}

It is difficult to understand why one small population of patients with dystonia (approximately $12 \%$ ) responds favorably to dopamine agonists while another subset, about twice as large, responds favorably to dopamine antagonist drugs (dopamine receptor blockers and dopamines torage depletors, such as tetrabenazine and reserpine), ${ }^{23-25}$ which have the opposite action. One commonly invoked explanation of this apparent incongruity is that torsion dystonia is the result of more than one pathophysiologic mechanism; patients with one type of dystonia respond to one class of drugs, and those with another type respond to different agents. At least consistent with this proposal is the absence of any description of an individual responding to both dopamine agonists and antagonists.

Lang $^{26}$ recently reviewed the literature on dopamine antagonists in the treatment of idiopathic dystonia. The results of these studies have been highly variable. For example, the frequency of response to these drugs in generalized and segmental dystonias varied from $0 \%$ to $78 \%$; for cranial dystonia, from $3 \%$ 
to $34 \%$; for spasmodic torticollis, from $9 \%$ to $46 \%$; and no patient with writer's cramp responded.

The most commonly used drugs of this class have been phenothiazines, haloperidol, tetrabenazine and pimozide. Marsden and colleagues ${ }^{10}$ recently reported that a triple combination of a dopamine depletor, a dopamine receptor blocker, and an anticholinergic may allow greater benefit in some patients than any of these drugs alone. From that study, it is not clear whether both the dopamine receptor blocker and the dopamine depletor are necessary in combination or whether a higher dosage of either would be equally effective. This "cocktail" was arrived at empirically. Tetrabenazine was kept at low dose (75-150 mg/day) because higher doses caused an unacceptable incidence of depression. Tetrabenazine depletes the brain not only of dopamine, but also of norepinephrine and serotonin, which may be involved with depression. Pimozide (a relatively selective dopamine receptor blocking agent) or haloperidol was added to increase dopamine antagonism. Trihexyphenidyl was included to prevent drug-induced parkinsonism and for its effect on dystonia.

In open-label trials of antidopaminergics in patients with idjopathic dystonia, we found "' that $35 \%$ of 26 patients showed moderate to marked benefit from dopamine receptor blockers, whereas $25 \%$ of 44 had such benefit from dopamine depletors. Most of these patients were also taking an anticholinergic drug. From this study, it appears that antidopaminergics are the second most effective class of drugs for the nonspecific treatment of idiopathic torsion dystonia in terms of percentage of patients who respond.

\section{Other Pharmacologic Agents}

There are only scattered reports on the efficacy of other drugs in the treatment of dystonia. Baclofen in high dosage has benefitted some patients with blepharospasm. ${ }^{27.28}$ This drug has now been studied in other forms of dystonia as well. Of 108 patients with a variety of idiopathic dystonias treated with baclofen, $20 \%$ of patients had a moderate to marked benefit." In the analysis of 58 patients with segmental cranial dystonia who were treated with baclofen, three-quarters of the 20 who responded favorably had a marked beneficial response. Apparently in this variety of dystonia, baclofen either fails to produce any beneficial effect or it produces a highly successful response.

The benzodiazepines have occasionally provided some benefit in anecdotal reports. ${ }^{29}$ We found 11 that clonazepam and other benzodiazepines were effective in $15 \%$ of 177 patients with idiopathic dystonia. There is no evidence of superiority of any one benzodiazepine. Jankovic and Ford ${ }^{24}$ reported that clonazepam is sometimes beneficial for Meige syndrome.

The initial highly enthusiastic reports on the effectiveness of carbamazepine in dystonia ${ }^{30.31}$ could not be substantiated by subsequent studies, which showed that only a small percentage of patients respond to this agent. ${ }^{32}$ In the large study by Greene et al, " of the 67 patients treated with carbamazepine, only $11 \%$ obtained moderate or greater benefit.

\section{SURGERY}

Stereotactic thalamotomy, at one time the most effective therapy for dystonia, is less often used because of the benefits seen with pharmacotherapy and the CNS complications that may accompany such surgery. Such therapy is particularly useful in contralateral hemidystonia. For this condition, only unilateral surgery is necessary. The risk of adverse effects is less than with bilateral thalamotomy. Today, thalamotomy should be employed only when dystonia is severely disabling and not responsive to pharmacotherapy.

\section{Choosing A Treatment Strategy}

No single drug is uniformly effective in treating dystonia, nor are surgical approaches uniformly beneficial or without risk. This poses a problem as to what should be the first choice of treatment in any given patient. Enough information is available from both open-label and double-blind drug trials and from surgical experience to draw some conclusions.

In order to avoid potential harm when searching for effective therapy, surgical procedures and the use of drugs that can cause irreversible complications are used late in empirical trials of treatments for dystonic patients. The focal dystonias have the therapeutic advantage that local injections of botulinum toxin and peripheral surgical denervation, which have a low risk of serious adverse effects, are effective in many patients. Since trials of botulinum toxin in patients with blepharospasm have consistently shown that $70 \%$ of patients improve for up to three months and can have continued improvement with subsequent injections, this may turn out to be the first line of treatment for this condition, particularly since systemically administered drugs have a lower success rate and more adverse effects. However, botulinum toxin is not commercially available and unti] it becomes so, most practicing physicians will not have access to it. Therefore, one should first use pharmacologic agents that have been shown to have some effectiveness in treating blepharospasm without producing permanent complications; these are anticholinergics, baclofen and tetrabenazine. If these drugs fail, the patient should be referred to investigators who have access to botulinum toxin. Antipsychotic drugs, such as haloperidol and the phenothiazines, although occasionally effective, may cause tardive dyskinesia and tardive dystonia, so I recommend avoiding them unless everything else fails. In fact, for blepharospasm I prefer facial nerve section or myectomy over the use of antipsychotic drugs. Table 1 summarizes the preferential order of treatment for blepharospasm.

Spasmodic torticollis, the most common focal dystonia, can also respond to botulinum toxin, but few studies have been published so far. Furthermore, the high dosages of botulinum toxin needed to sufficiently weaken the neck muscles, added to the possibility that such large doses may eventually result in development of antibodies or peripheral adverse effects, raises serious concerns as to the usefulness of botulinum toxin for spasmodic torticollis. Further trials and longer duration of follow-up of toxin injections are required, Drug trials should be the first approach, and I use the following order of drugs: anticholinergics, baclofen, carbamazepine and a benzodiazepine.

\begin{tabular}{l} 
Table 1: Order of Treatments for Blepharospasm \\
\hline 1. Botulinum toxin injections \\
2. Anticholinergic \\
3. Baclofen \\
4. Benzodiazepine \\
5. Tetrabenazine \\
6. Peripheral surgery
\end{tabular}


If these fail, tetrabenazine alone or in combination with pimozide or haloperidol, and with an anticholinergic ${ }^{10}$ can be tried. Table 2 summarizes the preferential order of treatment for torticollis.

Writer's cramp is probably the focal dystonia most resistant to pharmacological approaches. An occasional patient will respond to anticholinergics, but other drugs have not yet been found useful in this condition. Some investigators are evaluating botulinum toxin injection. If writer's cramp is limited to one side, I recommend having the patient learn to write with the other hand. If writer's cramp spreads to the other side [as it will do in about $33 \%$ of cases ${ }^{33}$ ], then a trial of anticholinergics is recommended. Table 3 summarizes the preferential order of treatment for writer's cramp.

Peripheral surgical denervation and botulinum toxin injections cannot be used to treat the segmental and generalized dystonias because of the greater number of muscles involved. Systemic pharmacologic agents and stereotactic thalamotomy are the only alternatives. Pharmacologic trials are always recommended before considering stereotactic thalamotomies.

It is best to begin with a short course of levodopa to see if the patient is in that small subset who responds to this agent. A dose of Sinemet, 5/50 mg t.i.d. or 10/100 mg t.i.d., can be used. If this fails, it is reasonable to increase the dose to a maximum of $25 / 250 \mathrm{mg}$ t.i.d. for 2 months before giving up on it.

The next drug to be tried is an anticholinergic agent. From the studies of Greene et al, " trihexyphenidyl is better tolerated in children than is ethopropazine, whereas the reverse is true in adults. The schedule for using anticholinergics is given above in the section on anticholinergics.

\section{Table 2: Order of Treatment for Torticollis}

1. Anticholinergics

2. Baclofen

3. Carbamazepine

4. Benzodiazepine

5. Tetrabenazine or reserpine

6. Dopamine receptor blocker

7. Botulinum toxin injections

8. Extraspinal selective peripheral denervation

\section{Table 3: Order of Treatment For Writer's Cramp}

1. Learn to write with the other arm

2. Anticholinergics

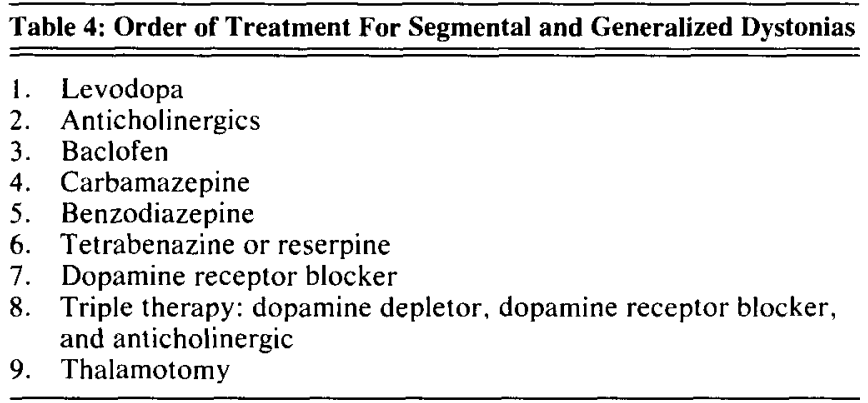

If a second drug is needed, I select from among baclofen, benzodiazepine and carbamazepine, since these agents do not cause any persistent adverse effects. Although dopamine receptor blockers are more effective than these three, they can cause persistent tardive dyskinesia and tardive dystonia. Thus, I use dopamine receptor blockers as a last resort. There is little difference between baclofen, benzodiazepine, and carbamazepine, and all three can be tested in any order. For baclofen I start at a dosage of $10 \mathrm{mg} /$ day and increase the daily dosage by $5 \mathrm{mg}$ every 4 days until either a maximum of $120 \mathrm{mg} /$ day, some therapeutic benefit, or limiting adverse effects are reached. I have been using clonazepam as the benzodiazepine for testing, but there is no information by which to determine if one benzodiazepine is superior to any other for this purpose. For clonazepam I start with $0.5 \mathrm{mg}$ h.s., and then increase the daily dosage by $0.5 \mathrm{mg}$ every 4 days until $6 \mathrm{mg} /$ day, benefit, or limiting adverse effects are reached. Clonazepam commonly produces a change in personality, well described by our name for it: "nasty syndrome." For carbamazepine I begin with 200 $\mathrm{mg}$ h.s. and then increase the daily dosage by $100 \mathrm{mg}$ every 4 days until $800 \mathrm{mg} /$ day, benefit, or limiting adverse effects are reached.

If these drugs fail, I then test an antidopaminergic. Again, the potential for producing tardive dyskinesia on top of idiopathic dystonia with this type of agent must be considered. It is possible that a dopamine depletor like tetrabenazine or reserpine can be used as a substitute for an antipsychotic drug since the depletors have not been reported to cause tardive dyskinesia or tardive dystonia. ${ }^{34}$ I use reserpine first, and if that is not tolerated because of adverse effects, I then evaluate tetrabenazine. The doses for these drugs have been described in the section on chorea. Table 4 summarizes the preferential order of treatment for the segmental and generalized dystonias.

As new centrally acting drugs are developed for other neurologic conditions they should be tested in dystonia as well, By empirical trials, a new effective therapeutic agent may be discovered.

\section{Conclusion}

Systemic pharmacotherapy is the treatment of first choice for almost all types of disabling (moderate to severe) dystonia, whether idiopathic or symptomatic, and whether focal, segmental or generalized. One currently evolving exception is the focal dystonia of blepharospasm, which can be treated with a high degree of success using botulinum toxin. Other focal dystonias can also be ameliorated by local injection of this toxin, but at this moment, this focal treatment should be considered investigational and be utilized after systemic pharmacotherapy has failed.

\section{REFERENCES}

1. Fahn S, Marsden CD, Calne DB. Classification and investigation of dystonia. In: Marsden CD, Fahn S, eds: Movement Disorders 2. London, Butterworth Scientific 1987: 332-358.

2. Herz E. Dystonia. I. Historical review: Analysis of dystonic symptoms and physiologic mechanisms involved. Arch Neurol Psychiat 1944; 51: 305-318.

3. Eldridge R. The torsion dystonias: Literature review and genetic and clinical studies. Neurology 1970; 20: No. 11 Part 2: 1-78. 
4. Burke RE, Fahn S, Jankovic J, et al. Tardive dystonia: Late-onset and persistent dystonia caused by antipsychotic drugs. Neurology 1982; 32: 1335-1346.

5. Fahn S. Treatment of dystonia with high-dosage anticholinergic medication. Neurology 1979; 29: 605 .

6. Fahn S. High dosage anticholinergic therapy in dystonia. Neurology $1983 ; 33$ : 1255-1261.

7. Burke RE, Fahn S, Marsden CD. Torsion dystonia: A doubleblind, prospective trial of high-dosage trihexyphenidyl. Neurology 1986;36: 160-164.

8. Duvoisin RC. Meige syndrome: Relief on high-dose anticholinergic therapy. Clinical Neuropharmacology 1983; 6: 63-66.

9. Lang AE. High dose anticholinergic therapy in adult dystonia. Canadian J Neurol Sci 1986; 13: 42-46.

10. Marsden CD, Marion M-H, Quinn N. The treatment of severe dystonia in children and adults. J Neurol Neurosurg Psychiatry 1984; 47: 1166-1173.

11. Greene PE, Shale H, Fahn S. Analysis of a large series of patients with torsion dystonia treated with high dosages of anticholinergic and other drugs. Advances in Neurology. In press.

12. Lang AE. Dopamine agonists in the treatment of dystonia. Clinical Neuropharmacology $1985 ; 8: 38-57$.

13. Segawa M, Hosaka A, Miyagawa F, et al. Hereditary progressive dystonia with marked diurnal fluctuation. Adv Neurol 1976; 14: 215-233.

14. Deonna T. DOPA-sensitive progressive dystonia of childhood with fluctuations of symptoms: Segawa's syndrome and possible variants. Neuropediatrics 1986; 17: 81-85.

15. Rondot P, Ziegler M. Dystonia - L-dopa responsive or juvenile parkinsonism? J Neural Transm Suppl 1983; 19: 273-281.

16. Nygaard TG, Marsden CD, Duvoisin RC. Dopa-responsive dystonia. Advances in Neurology. In press.

17. Burns CLC. The treatment of torsion spasm in children with trihexyphenidyl (Artane). The Medical Press 1959;241: 148-149.

18. Corner BD. Dystonia musculorum deformans in siblings treated with Artane (trihexyphenidyl). Proc Royal Soc Med 1952; 45: $51-452$.

19. Newman RP, LeWitt PA, Shults C, et al. Dystonia: treatment with bromocriptine. Clinical Neuropharmacology 1985; 8: 328-333.
20. Nutt JG, Hammerstad JP, Carter JH, et al. Lisuride treatment of focal dystonias. Neurology $1985 ; 35: 1242-1243$.

21. Quinn NP, Lang AE, Sheehy MP, et al. Lisuride in dystonia. Neurology 1985; 35: 766-769.

22. Stahl SM, Berger PA. Bromocriptine, physostigmine, and neurotransmitter mechanisms in the dystonias. Neurology 1982; 32: 889-892.

23. Jankovic J. Treatment of hyperkinetic movement disorders with tetrabenazine: A double-blind crossover study. Ann Neurol 1982; 11: 1-47.

24. Jankovic J, Ford J. Blepharospasm and orofacial-cervical dystonia: clinical and pharmacological findings in 100 patients. Ann Neurol 1983; 13: 402-411.

25. Lang AE, Marsden CD. Alphamethylparatyrosine and tetrabenazine in movement disorders. Clinical Neuropharmacology 1982; 5: $375-387$.

26. Lang AE. Dopamine agonists and antagonists in the treatment of idiopathic dystonia. Advances in Neurology 1987. In press.

27. Fahn S, Hening WA, Bressman S, et al. Long-term usefulness of baclofen in the treatment of essential blepharospasm. Advances in Ophthalmic Plastic Reconstructive Surgery 1985; 4: 219-226.

28. Gollomp SM, Fahn S, Burke RE, et al. Therapeutic trials in Meige syndrome. Advances in Neurology 1983; 37: 207-213.

29. Ziegler DK. Prolonged relief of dystonic movements with diazepam. Neurology 1981; 31: 1457-1458.

30. Girotti F, Scigliano G, Nardocci N, et al. Idiopathic dystonia: neuropharmacologic study. J Neurol 1982; 227: 239-247.

31. Geller M, Kaplan B, Cristoff N. Treatment of dystonia symptoms with carbamazepine. Advances in Neurology 1976; 14: 403-410.

32. Isgreen WP, Fahn S, Barrett RE, et al. Carbamazepine in torsion dystonia. Advances in Neurology 1976; 14: 411-416.

33. Sheehy MP, Marsden CD. Writer's cramp - a focal dystonia. Brain 1982; 105: 461-480.

34. Fahn S. The tardive dyskinesias. In: Matthews WB, Glaser GH, eds: Recent Advances in Clinical Neurology. Churchill Livingstone, Edinburgh, 1984; 4: 229-260. 